\title{
Carbonisation of Resorcinol-Formaldehyde Organic Xerogels: Effect of Temperature, Particle Size and Heating Rate on the Porosity of Carbon Xerogels
}

\author{
A.H. Moreno, A. Arenillas, E.G. Calvo, J.M. Bermúdez, J.A. Menéndez* \\ Instituto Nacional del Carbón, CSIC. Apartado 73. 33080 Oviedo, Spain
}

\begin{abstract}
Resorcinol-Formaldehyde organic xerogels with an initial pH of 6.5 were synthesized in a microwave oven and then carbonised in a furnace. The influence of the carbonisation temperature, heating rate and the particle size of the organic xerogels upon the pore structure of the carbon xerogels was assessed. The textural properties of the organic and carbon xerogels were evaluated from $\mathrm{N}_{2}$ adsorption-desorption isotherms at $-196^{\circ} \mathrm{C}$ and by measuring the true (helium) density. As the carbonisation temperature increased from 700 to $950^{\circ} \mathrm{C}$ the $\mathrm{S}_{\mathrm{BET}}$ of the carbon xerogels decreased from 585 to $471 \mathrm{~m}^{2} \mathrm{~g}^{-1}$ for the carbon xerogels derived from the organic xerogels crushed to a particle size $>212 \mu \mathrm{m}$. A decrease in the particle size to dp $<212 \mu \mathrm{m}$ caused an increase in the BET specific surface area of the carbon xerogels of between 12 and $27 \%$ but also a decrease of the carbon xerogel yield of between 15 and $24 \%$, depending on the carbonisation temperature. The pore structure of the carbon xerogels did not change significantly with the increase in the heating rate in the carbonisation process over the interval studied.
\end{abstract}

Keywords: Carbon xerogels, carbonisation, textural properties, pore structure 


\section{Introduction}

Organic xerogels are mesoporous carbon materials, obtained from the polycondensation of resorcinol with formaldehyde in a solvent (i.e. water, methanol, acetone, etc.). The synthesis of these materials involves two main steps: (i) gel synthesis, during which the stages of gelation and curing take place and (ii) the drying of the gel saturated with solvent. The dried organic xerogels obtained are carbonised in an inert atmosphere (i.e. $\mathrm{N}_{2}, \mathrm{Ar}, \mathrm{He}$ ), in a third stage, to produce carbon xerogels.

Carbon xerogels are microporous carbon materials that have received considerable attention in the literature over the past decade [1-3]. These materials can be produced in different forms (as powder, thin-film, cylinders, spheres, discs, or can be custom-shaped) [3]. The most important properties of these materials are: their high porosity, surface area and pore volume, controllable pore structure, narrow and controlled pore size distribution, low electrical resistivity and outstanding thermal and mechanical properties. These properties make them promising materials for several potential applications: as electrode material for double layer capacitors or supercapacitors [4-9], adsorption materials for gas separation [10-12], catalyst supports [13-17], column packing materials for chromatography [18] and for $\mathrm{H}_{2}$ storage [19].

Organic xerogels, obtained after the drying step, usually have a specific surface area $\left(\mathrm{S}_{\mathrm{BET}}\right)$ of less than $500 \mathrm{~m}^{2} \mathrm{~g}^{-1}[20-22]$. In contrast, carbon xerogels, after the carbonisation step, generally present a more developed microporosity which results in a surface area $\left(\mathrm{S}_{\mathrm{BET}}\right)$ of $500-700 \mathrm{~m}^{2} \mathrm{~g}^{-1}[8,20-24]$. 
The synthesis [8,20,24-26] and drying [21,22,27-30] steps of organic xerogels have been extensively studied. However, only a few works have focused on the variables characteristic of the carbonisation stage (e. g. carbonisation temperature).

The carbonisation of organic xerogels is influenced by several factors such as the carbonisation temperature, heating rate, residence time in the reaction zone, particle size, fluid dynamics within the reactor, etc.

During carbonisation, organic xerogel particles are heated at a pre-established rate from room temperature to the required pyrolysis temperature, which generally ranges from 600 to $1050^{\circ} \mathrm{C}$, although sometimes higher temperatures $\left(1500-2100^{\circ} \mathrm{C}\right)$ have also been employed $[31,32]$. The xerogel particles are held at the pyrolysis temperature for a specified time until the carbonisation process is completed. Previous studies on the carbonisation of organic aerogels [33-36] and xerogels [20,23] have shown that the carbonisation temperature has a significant influence on the pore structure of carbon aerogels and xerogels. However, in these studies the organic xerogels and aerogels were synthesized by conventional methods using other catalysts (i.e. $\mathrm{Na}_{2} \mathrm{CO}_{3}, \mathrm{~K}_{2} \mathrm{CO}_{3}, \mathrm{KHCO}_{3}$, and $\mathrm{NaHCO}_{3}$ ). In addition, little attention has been paid to analyzing the influence of other variables such as the particle size of the organic xerogels and heating rate, during the carbonisation process, upon the pore structure of the carbon xerogels. Moreover, only low heating rates $\left(<10^{\circ} \mathrm{C} \min ^{-1}\right)$ are generally used to obtain carbon xerogels $[23,25]$ and aerogels $[5,35,37]$ and normally several stages of heating, at very low heating rates (i.e. $1.7-5^{\circ} \mathrm{C} \mathrm{min}^{-1}$ ), have been employed [8,20-22,24,38,39]. This makes the carbonisation process more difficult to perform and a longer time is needed to reach the desired carbonisation temperature and, therefore, to obtain the carbon xerogels. Hence, these conditions constitute a serious obstacle to the production of carbon xerogels and their implementation on an industrial scale. It is clearly necessary to reduce the time required to 
reach the carbonisation temperature and to simplify the carbonisation process in order to make carbon gels more competitive with respect to other materials (i.e. activated carbons).

The purpose of this work is to study the effect of the carbonisation temperature, heating rate and particle size of the organic xerogels upon the porosity of carbon xerogels.

\section{Material and Methods}

2.1. Synthesis of the organic xerogels

The organic xerogels used in this study were obtained from the microwave-assisted synthesis of a solution prepared from the monomers Resorcinol (R) and Formaldehyde (F), using deionised water as solvent and a sodium hydroxide solution (1 $\mathrm{M})$ as catalyst to adjust the precursor solution to a $\mathrm{pH}$ of 6.5 . In this technology all stages (gelation, curing and drying) were performed in a simple and fast device, a microwave oven, at atmospheric pressure and low temperature $\left(<100^{\circ} \mathrm{C}\right)$. This alternative and competitive technology allows preparing organic xerogels in only 6-7 hours, a 75\% faster than others synthesis methods, with similar textural and chemical properties to those produced by conventional methods used so far. Full details of the experimental set-up can be found elsewhere [24].

Two series of organic xerogels of different particle size were prepared to obtain the carbon xerogels. In the first series, the organic xerogel was crushed to a particle size of $>212 \mu \mathrm{m}$ (dp $>212 \mu \mathrm{m})$ and this series was denoted OX-6.5+212. In the second, the organic xerogel was ground to below $212 \mu \mathrm{m}$ and this series was labelled OX-6.5-212. The first two letters 
represent the type of xerogel (OX for organic xerogel). These letters are followed by the $\mathrm{pH}$ of the resorcinol-formaldehyde solution (6.5) and the last three figures represent the particle size of the organic xerogel used.

2.2. Temperature Programmed Carbonisation of the organic xerogels in a thermobalance

A Temperature-programmed carbonisation experiment was performed in a thermobalance (TA Instruments, Q $5000 \mathrm{IR}$ ), where $10 \mathrm{mg}$ of the organic xerogel ground to below $0.212 \mathrm{~mm}$ was placed in a platinum crucible and heated at a heating rate of $15^{\circ} \mathrm{C} \min ^{-1}$ from room temperature to $1000^{\circ} \mathrm{C}$, under a nitrogen flow rate of $25 \mathrm{~mL} \mathrm{~min}^{-1}$.

2.3. Carbonisation of the organic xerogels in a horizontal tube reactor

The carbonisation of the organic xerogels was performed in a quartz reactor (i.d. $30 \mathrm{~mm}$ ) placed in a horizontal electrical tube furnace (Carbolite Type MFT 12/38/400), under a nitrogen flow rate of $100 \mathrm{mLmin}^{-1}$ and a soaking time of $2 \mathrm{~h}$ in all the cases studied. The carbonised RF carbon xerogel particles were cooled down to room temperature under the same nitrogen flow rate.

Three carbon xerogels series were obtained. In the first series, the organic xerogel OX$6.5+212$ was carbonised using a heating rate of $5^{\circ} \mathrm{C} \min ^{-1}$ from room temperature to six different final temperatures $\left(700,750,800,850,900\right.$ and $\left.950^{\circ} \mathrm{C}\right)$. In the second series, the organic xerogel $\mathrm{OX}-6.5-212$ was pyrolized at a heating rate of $5^{\circ} \mathrm{C} \mathrm{min}^{-1}$ from room temperature to three different final temperatures $\left(700,800\right.$ and $\left.900^{\circ} \mathrm{C}\right)$. In the last series, the 
organic xerogel OX-6.5-212 was carbonised at a temperature of $850^{\circ} \mathrm{C}$ using six different heating rates $\left(5,10,20,30,40\right.$ and $\left.50^{\circ} \mathrm{C} \mathrm{min}^{-1}\right)$.

The carbon xerogels obtained were labelled as follows. The first two letters represent the type of xerogel (CX for carbon xerogels). These letters are followed by the $\mathrm{pH}$ of the resorcinolformaldehyde solution and the particle size in the same way as the organic xerogels described in section 2.1. The last figures indicate the carbonisation temperature and heating rate used to obtain the carbon xerogel. For example, the label CX-6.5-212-850-50 indicates a carbon xerogel obtained from a resorcinol-formaldehyde solution with a $\mathrm{pH}$ of 6.5 , a particle size of less than 212 micron at a carbonisation temperature of $850^{\circ} \mathrm{C}$ using a heating rate of $50^{\circ} \mathrm{C}$ $\min ^{-1}$

\subsection{Porous characterisation of RF carbon xerogels}

The textural properties of the organic and carbon xerogels were evaluated from $\mathrm{N}_{2}$ adsorptiondesorption isotherms at $-196^{\circ} \mathrm{C}$ and by measuring the true (helium) density. The adsorption analysis was carried out with a Micromeritics Tristar 3000, for the study of microporosity and narrow mesoporosity. Before measuring the adsorption isotherms the samples were heated overnight to $120^{\circ} \mathrm{C}$ under vacuum to remove all of the physisorbed species.

The micropore volume ( $\mathrm{V}_{\text {DUB-N2}}$ ) was evaluated by applying the Dubinnin-Raduskevich (DR) equation to the $\mathrm{N}_{2}\left(\mathrm{Wo}_{\mathrm{O}} \mathrm{N}_{2}\right)$ adsorption isotherms, and the total pore volume $\left(\mathrm{V}_{\mathrm{p}}\right)$ was calculated from the adsorbed volume at saturation $\left(\mathrm{p} / \mathrm{p}^{\mathrm{o}}=0.95\right)$. The Brunauer-Emmett-Teller (BET) surface area $\left(\mathrm{S}_{\mathrm{BET}}\right)$ was estimated from the nitrogen adsorption isotherms.

The true densities of the RF carbon xerogels were measured in a Micromeritics AccuPyc 1340 Pycnometer. Before measuring the helium density the samples were outgassed overnight under vacuum at $120^{\circ} \mathrm{C}$. 


\section{Results and Discussion}

3.1. Temperature-programmed carbonisation of the organic xerogels in a thermobalance

The variation in mass loss (TG) and the rate of mass loss (DTG) of the OX-6.5-212 with temperature, during the temperature-programmed carbonisation experiment, are shown in Figure 1. As can be seen, mass loss occurs up to a temperature of $750^{\circ} \mathrm{C}$, where the mass loss reaches $50 \%$. This result agrees with the findings of other authors [20,23]. However, the mass loss is not constant and three stages of mass loss can be clearly observed.

The rate of mass loss shows three maxima with the increase in temperature, as can be seen in Figure 1. The first peak appears at a low temperature $\left(<100^{\circ} \mathrm{C}\right)$, whereas the other two peaks appear at higher temperatures (around $370^{\circ} \mathrm{C}$ and $600^{\circ} \mathrm{C}$ ). According to Job et al [20], the first peak probably corresponds to the extraction of the remaining solvent and/or the elimination of $\mathrm{H}_{2} \mathrm{O}$ formed from the condensation of $-\mathrm{OH}$ groups, while the second peak is attributed to hydrogen and oxygen atoms in the polymer network being released as $\mathrm{CO}_{2}$ and $\mathrm{CH}_{4}$ or other organic molecules, and probably to the desorption of adsorbed organic compounds [20]. Moreover, the elimination of carbon, oxygen and hydrogen continues as the temperature rises, leading to a third peak. Most of the carbonisations of the organic xerogels reported in the bibliography were performed in three steps as in this study [20], i. e., heating the xerogel very slowly and maintaining the temperature for certain period of time $[8,20-22,24,38,39]$. 


\subsection{Effect of carbonisation temperature on the porosity of carbon xerogels}

The effect of the carbonisation temperature on the porosity of the carbon xerogels is shown in Figures 2-3. Figure 2 shows the adsorption-desorption isotherms of nitrogen at $-196^{\circ} \mathrm{C}$ corresponding to the carbon xerogels, obtained from the carbonisation of the first series of organic xerogels $(\mathrm{OX}-6.5+212)$ at three different temperatures $\left(750,850\right.$ and $\left.950^{\circ} \mathrm{C}\right)$. As can be seen, all of the adsorption-desorption isotherms are similarly shaped, and are a combination of type I and type IV, according to the IUPAC classification [40], which are typical of materials that contain micro and mesoporosity. The isotherms show a hysteresis loop, indicative of mesoporosity. It should also be pointed out that all the samples, including the organic xerogel, present a hysteresis loop of similar size and shape indicating a similar mesopore size and volume. The rectangular shape of the isotherms at very low relative pressures is indicative of the presence of microporosity. It can be observed that the carbonisation step produces an increase in the volume of nitrogen adsorbed at low relative pressures indicating the creation of microporosity with carbonisation.

The organic xerogel with a $\mathrm{pH}$ of $6.5(\mathrm{OX}-6.5+212)$ is mainly a mesoporous solid, with low microporosity and negligible macroporosity development. The latter has been corroborated by mercury porosimetry results published in a previous work [24].

Figure 2 also illustrates, in the inset, the pore size distribution of the samples obtained from NLDFT method applied to the adsorption-desorption isotherms of nitrogen at $-196^{\circ} \mathrm{C}$. It can be seen that the pores are distributed in the region of micropores and mesopores. In the micropore region all samples exhibit a common peak between around $1.3 \mathrm{~nm}$, indicating the presence of certain microporosity. On the other hand, all mesopores present a size below 18 nm. 


\subsection{Effect of the particle size on the carbonisation of carbon xerogels}

The BET specific surface areas of the carbon xerogel particles, obtained from the carbonisation of the two series of organic xerogels (OX-6.5+212 and OX-6.5-212) at different temperatures, are shown in Figure 3. It can be seen that as the carbonisation temperature increases, the $\mathrm{S}_{\mathrm{BET}}$ of the carbon xerogels (series OX-6.5+212) tends to decrease, especially in the case of the carbonisation temperatures higher than $850^{\circ} \mathrm{C}$. This trend agrees with the results of other researchers in the same interval of carbonisation temperature, both for carbon aerogels $[33,34,36]$ and for carbon xerogels [20,23]. One possible explanation for the decrease of micropore volume with the increase of carbonisation temperature is the reorganisation of the structure leading to a partial collapse of the micropores, which leads to a more ordered structure and hence to a lower specific surface area.

However, this trend is not observed in the case of the organic xerogel ground to below 212 $\mu \mathrm{m}$ (Series OX-6.5-212), where the $\mathrm{S}_{\mathrm{BET}}$ of the carbon xerogels obtained at different carbonisation temperatures is nearly equal $\left(\sim 650 \mathrm{~m}^{2} \mathrm{~g}^{-1}\right)$. It seams that the particle size of the organic xerogels have an influence on this reorganisation reactions at higher carbonisation temperatures, minimising this collapse of the micropores that contribute to the BET specific surface area. Moreover, as can be seen in Figure 3 the surface areas of the carbon xerogels obtained from the OX-6.5-212 series are between 68 and $140 \mathrm{~m}^{2} \mathrm{~g}^{-1}$ higher than those obtained from the OX-6.5+212 series.

The helium densities of the carbon xerogels, obtained from the carbonisation of two series of organic xerogel $(\mathrm{OX}-6.5+212$ and $\mathrm{OX}-6.5-212)$ at different temperatures, are presented Figure 4. In this figure there is a continuous increase in the densities of the carbon xerogel particles with the rise in carbonisation temperature. The increase in the true density is due to 
the removal of less organised materials and the opening of closed pores. These effects are heavily dependent on the operating temperature, necessary for the release of volatiles. However it seems that this densification occurred is a bit different depending on the particle size of the organic xerogel, as in the case of the series OX-6.5+212 affects the micropore volume determined by the adsorption of $\mathrm{N} 2$ at $-196^{\circ} \mathrm{C}$ but not in the case of the sample with lower particle size (OX-6.5-212).

The carbon xerogel yield, obtained from the carbonisation of organic xerogels at different temperatures, is also dependent on the particle size. Therefore, the series OX-6.5+212 developed lower surface area but leads to a $10 \%$ higher of carbon xerogel yield after carbonisation than in the case of the series OX-6.5-212 (ca. 54 wt\% versus 44 wt $\%$, respectively). In sum, the textural properties and yield of carbon xerogels are influenced by the temperature used during carbonisation and by the particle size of the organic precursor used.

\subsection{Effect of heating rate on the porosity of the carbon xerogels}

The effect of different heating rates during the carbonisation of organic xerogels in the OX6.5-212 series, upon the BET specific surface area of the carbon xerogels is shown in Figure 5. As can be seen the BET specific surface area of the carbon xerogels increases slightly from 626 to $650 \mathrm{~m}^{2} \mathrm{~g}^{-1}$, as the heating rate of the carbonisation process increases from 5 to $20^{\circ} \mathrm{C} \min ^{-1}$. At higher heating rates $\left(30,40\right.$ and $\left.50^{\circ} \mathrm{C} \min ^{-1}\right)$ the BET specific surface area of the carbon xerogels remains nearly constant at around $640 \mathrm{~m}^{2} \mathrm{~g}^{-1}$. This evidences that the carbonisation process to obtain carbon xerogels can be performed at higher heating rates than those traditionally reported in the bibliography. It should also be noted that the time required 
to reach the carbonisation temperature of $850^{\circ} \mathrm{C}$ decreases from 2.77 to $0.30 \mathrm{~h}$ (a saving of time of $89 \%$ ) when the furnace heating rates are increased from 5 to $50^{\circ} \mathrm{C} \mathrm{min}^{-1}$.

In contrast, the carbon xerogel yields, obtained at different heating rates during the carbonisation of the organic xerogels, remained at around $44 \%$ and no significant changes were observed with the increase in the heating rates from 5 to $50^{\circ} \mathrm{C} \mathrm{min}^{-1}$.

In sum, the pore structure and the yield of carbon xerogels do not change significantly with the increase in heating rate during carbonisation over the interval studied.

\section{Conclusions}

From an analysis of the results obtained in this work the following conclusions can be drawn.

The particle size of the organic xerogels plays a very important role during the carbonisation process. A decrease in particle size to $\mathrm{dp}<212 \mu \mathrm{m}$ caused an increase in the BET specific surface area of the carbon xerogels of between 12 and $27 \%$ but also a decrease in the carbon xerogel yield of between 15 and 24\%, depending on the carbonisation temperature used.

The carbonisation temperature has a significant effect on the textural properties of the carbon xerogels, when the organic xerogels have not been ground. An increase in the carbonisation temperature causes a decrease in porosity. However, the influence of the carbonisation temperature is negligible in the case of particles of size $<212 \mu \mathrm{m}$.

The heating rate at which the particles of organic xerogels are heated to the desired carbonisation temperature, in the interval studied, does not have any a significant influence on the BET specific surface area, pore structure or carbon xerogel yield. The use of higher 
heating rates (i.e. $50^{\circ} \mathrm{C} \mathrm{min}^{-1}$ ) during the carbonisation of organic xerogels allows the desired carbonisation temperature to be reached in a much shorter time (almost $90 \%$ less) than by the conventional method (i.e. heating rates of $5^{\circ} \mathrm{C} \min ^{-1}$ ) with a considerable saving of energy and costs. This saving of time makes the production method of carbon xerogels much more competitive. However, for its implementation on an industrial scale a fast or flash pyrolysis process needs to be devised.

In order to obtain carbon xerogels more quickly and with high specific surface areas upon pyrolysis the following conditions must be applied: an organic xerogel particle size lower than 212 micron, a heating rate of $50^{\circ} \mathrm{C} \mathrm{min}^{-1}$ and a carbonisation temperature of $700^{\circ} \mathrm{C}$.

\section{Acknowledgments}

Financial support from the Ministerio de Economía y Competitividad (Ref. MAT2011-23733) is greatly acknowledged. A.H. Moreno and E.G. Calvo are also grateful to FICYT for their postdoctoral and predoctoral research grant, respectively.

\section{References}

[1] S.B. Al-Muhtased and J.A. Ritter, Preparation and Properties of Resorcinol-Formaldehyde Organic and Carbon Gels, Advanced Materials. 15 (2003) 101-114.

[2] A.M. Elkhatat and S.A. Al-Muhtaseb, Advances in tailoring resorcinol-formaldehyde organic and carbon gels, Advanced Materials 23 (2011) 2887-2903.

[3] E.G. Calvo, J.A. Me . Arenillas, Designing Nanostructured Carbon Xerogels, in P.M. Rahman (Ed.), Nanomaterials, InTech, , Rijeka, 2011, Chapter 9, pp. 87-234.

[4] R.W.F. Pekala, J. C.; Alviso, C. T.; Tran, T. D.; Mayer, S. T. and B.D. J.M. Miller c, Carbon aerogels for electrochemical applications, Journal of Non-Crystalline Solids 225 (1998) 74-80. 
[5] R.F. Saliger, U.; Herta, C.; Fricke, J., High surface area carbon aerogels for supercapacitors, Journal of Non-Crystalline Solids 225 (1998) 81-85.

[6] E. Frackowiak and F. Béguin, Carbon materials for the electrochemical storage of energy in capacitors, Carbon 39 (2001) 937-950.

[7] J. Zhou, Y. Ji, J. He, C. Zhang and G. Zhao, Enhanced mesoporosity and capacitance property of spherical carbon aerogel prepared by associating $\mathrm{Mg}(\mathrm{OH}) 2$ with non-ionic surfactant, Microporous and Mesoporous Materials 114 (2008) 424-430.

[8] E.G. Calvo, C.O. Ania, L. Zubizarreta, J.A. Menéndez and A. Arenillas, Exploring new routes in the synthesis of carbon xerogels for their application in electric double-layer capacitors, Energy and Fuels 24 (2010) 3334-3339.

[9] F. Lufrano, P. Staiti, E.G. Calvo, E.J. Juárez-Pérez, J.A. Menéndez and A. Arenillas, Carbon Xerogel and Manganese Oxide Capacitive Materials for Advanced Supercapacitors, International Journal of Electrochemical Science 6 (2011) 596-612.

[10] T. Yamamoto, A. Endo, T. Ohmori and M. Nakaiwa, Porous properties of carbon gel microspheres as adsorbents for gas separation, Carbon 42 (2004) 1671-1679.

[11] D. Jayne, Y. Zhang, S. Haji and C. Erkey, Dynamics of removal of organosulfur compounds from diesel by adsorption on carbon aerogels for fuel cell applications, International Journal of Hydrogen Energy 30 (2005) 1287-1293.

[12] K.Y. Kang, B.I. Lee and J.S. Lee, Hydrogen adsorption on nitrogen-doped carbon xerogels, Carbon 47 (2009) 1171-1180.

[13] N. Job, B. Heinrichs, F. Ferauche, F. Noville, J. Marien and J.P. Pirard, Hydrodechlorination of 1,2-dichloroethane on $\mathrm{Pd}-\mathrm{Ag}$ catalysts supported on tailored texture carbon xerogels, Catalysis Today 102-103 (2005) 234-241.

[14] N. Job, B. Heinrichs, S. Lambert, J.P. Pirard, J.F. Colomer, B. Vertruyen and J. Marien, Carbon xerogels as catalyst supports: Study of mass transfer, AIChE Journal 52 (2006) 26632676.

[15] N. Job, M.F. Ribeiro Pereira, S. Lambert, A. Cabiac, G. Delahay, J.F. Colomer, J. Marien, J.L. Figueiredo and J.P. Pirard, Highly dispersed platinum catalysts prepared by impregnation of texture-tailored carbon xerogels, Journal of Catalysis 240 (2006) 160-171.

[16] N. Mahata, A.R. Silva, M.F.R. Pereira, C. Freire, B. de Castro and J.L. Figueiredo, Anchoring of a $[\mathrm{Mn}($ salen $) \mathrm{Cl}]$ complex onto mesoporous carbon xerogels, Journal of Colloid and Interface Science 311 (2007) 152-158.

[17] N. Job, J. Marie, S. Lambert, S. Berthon-Fabry and P. Achard, Carbon xerogels as catalyst supports for PEM fuel cell cathode, Energy Conversion and Management 49 (2008) 2461-2470.

[18] T. Yamamoto, T. Sugimoto, T. Suzuki, S.R. Mukai and H. Tamon, Preparation and characterization of carbon cryogel microspheres, Carbon 40 (2002) 1345-1351.

[19] L. Zubizarreta, J.A. Menéndez, N. Job, J.P. Marco-Lozar, J.P. Pirard, J.J. Pis, A. LinaresSolano, D. Cazorla-Amorós and A. Arenillas, Ni-doped carbon xerogels for H2 storage, Carbon 48 (2010) 2722-2733.

[20] N. Job, R. Pirard, J. Marien and J.P. Pirard, Porous carbon xerogels with texture tailored by $\mathrm{pH}$ control during sol-gel process, Carbon 42 (2004) 619-628.

[21] N. Job, A. Théry, R. Pirard, J. Marien, L. Kocon, J.N. Rouzaud, F. Béguin and J.P. Pirard, Carbon aerogels, cryogels and xerogels: Influence of the drying method on the textural properties of porous carbon materials, Carbon 43 (2005) 2481-2494.

[22] L. Zubizarreta, A. Arenillas, J.A. Menéndez, J.J. Pis, J.P. Pirard and N. Job, Microwave drying as an effective method to obtain porous carbon xerogels, Journal of Non-Crystalline Solids 354 (2008) 4024-4026.

[23] C. Lin and J.A. Ritter, Carbonization and activation of sol-gel derived carbon xerogels, Carbon 38 (2000) 849-861. 
[24] E.G. Calvo, E.J. Juárez-Pérez, J.A. Menéndez and A. Arenillas, Fast microwave-assisted synthesis of tailored mesoporous carbon xerogels, Journal of Colloid and Interface Science 357 (2011) 541-547.

[25] C. Lin and J.A. Ritter, Effect of Synthesis $\mathrm{pH}$ on the Structure of Carbon Xerogels, Carbon 35 (1997) 1271-1278.

[26] L. Zubizarreta, A. Arenillas, A. Domínguez, J.A. Menendez and J.J. Pis, Development of microporous carbon xerogels by controlling synthesis conditions, Journal of Non-Crystalline Solids 354 (2008) 817-825.

[27] O. Czakkel, K. Mar

, Influence of drying on the morphology of resorcinol-formaldehyde-based carbon gels, Microporous and Mesoporous Materials 86 (2005) 124-133.

[28] A. Leonard, N. Job, W. Jomaa, J.P. Pirard, M. Crine and J.R. Puiggali, Textural comparison of resorcinol-formaldehyde xerogels obtained by vacuum drying and convective drying, at: 102-103.

, Towards the production of

carbon xerogel monoliths by optimizing convective drying conditions, Carbon 44 (2006) 2534-2542.

[30] A. Léonard, S. Blacher, M. Crine and W. Jomaa, Evolution of mechanical properties and final textural properties of resorcinol-formaldehyde xerogels during ambient air drying, Journal of Non-Crystalline Solids 354 (2008) 831-838.

[31] G.A.M. Reynolds, A.W.P. Fung, Z.H. Wang, M.S. Dresselhaus and R.W. Pekala, The effects of external conditions on the internal structure of carbon aerogels, Journal of NonCrystalline Solids 188 (1995) 27-33.

[32] G. Reichenauer, A. Emmerling, J. Fricke and R.W. Pekala, Microporosity in carbon aerogels, Journal of Non-Crystalline Solids 225 (1998) 210-214.

[33] R.W.A. Pekala, C.T.; Kong, F.M.; Hulsey, S.S., Aerogels derived from multifunctional organic monomers, Journal of Non-Crystalline Solids 145 (1992) 90-98.

[34] S.Q. Zhang, J. Wang, J. Shen, Z.S. Deng, Z.Q. Lai, B. Zhou, S.M. Attia and L.Y. Chen, The Investigation of the Adsorption Character of Carbon Aerogels, NanoStructured Materials 11 (1999) 375-381.

[35] T. Horikawa, J. Hayashi and K. Muroyama, Size control and characterization of spherical carbon aerogel particles from resorcinol-formaldehyde resin, Carbon 42 (2004) 169-175.

[36] S.S. Hulsey, C.T. Alviso, F.M. Kong and R.W. Pekala, in Materials Research Society 1992 Spring Meeting, San Franscisco, CA, 1992, p. Medium: X; Size: 9 p.

[37] H.I. Tamon, H.; Mikami, M.; Okazaki, M., Porous Structure of Organic and Carbon Aerogels Synthesized by Sol-Gel Polycondensation of Resorcinol with Formaldehyde, Carbon 35 (1997) 791-796.

[38] L. Zubizarreta, A. Arenillas, J.P. Pirard, J.J. Pis and N. Job, Tailoring the textural properties of activated carbon xerogels by chemical activation with $\mathrm{KOH}$, Microporous and Mesoporous Materials 115 (2008) 480-490.

[39] M.S. Contreras, C.A. Paez, L. Zubizarreta, A. Leonard, S. Blacher, C.G. OliveraFuentes, A. Arenillas, J.P. Pirard and N. Job, A comparison of physical activation of carbon xerogels with carbon dioxide with chemical activation using hydroxides, Carbon 48 (2010) 3157-3168.

[40] K.S.W. Sing, D.H. Everett, R.A.W. Haul, L. Moscou, R.A. Pierotti, J. Rouquérol and T. Siemieniewska, Reporting physisorption data for gas/solid systems with Special Reference to the Determination of Surface Area and Porosity, Pure \& Applied Chemistry 57 (1985) 603619. 


\section{List of figures:}

Figure 1. Evolution of mass loss (TG) and mass loss rate (DTG) with temperature during the temperature programmed carbonisation of the organic xerogel OX-6.5-212.

Figure 2. $\mathrm{N}_{2}$ adsorption-desorption isotherms at $-196^{\circ} \mathrm{C}$ and Pore Size Distribution of the organic xerogel OX-6.5+212 and the carbon xerogels (Series OX$6.5+212$ ) carbonised at different temperatures.

Figure 3. Variation of the specific surface area $\left(\mathrm{S}_{\mathrm{BET}}\right)$ of carbon xerogels with the carbonisation temperature and with the particle size of the organic xerogels.

Figure 4. Variation of the helium (true) density of carbon xerogels with the carbonisation temperature and with the particle size of the organic xerogels.

Figure 5. Variation of the specific surface area $\left(\mathrm{S}_{\mathrm{BET}}\right)$ of the carbon xerogels, and the time required to reach $850^{\circ} \mathrm{C}$, with the pyrolysis heating rate. 


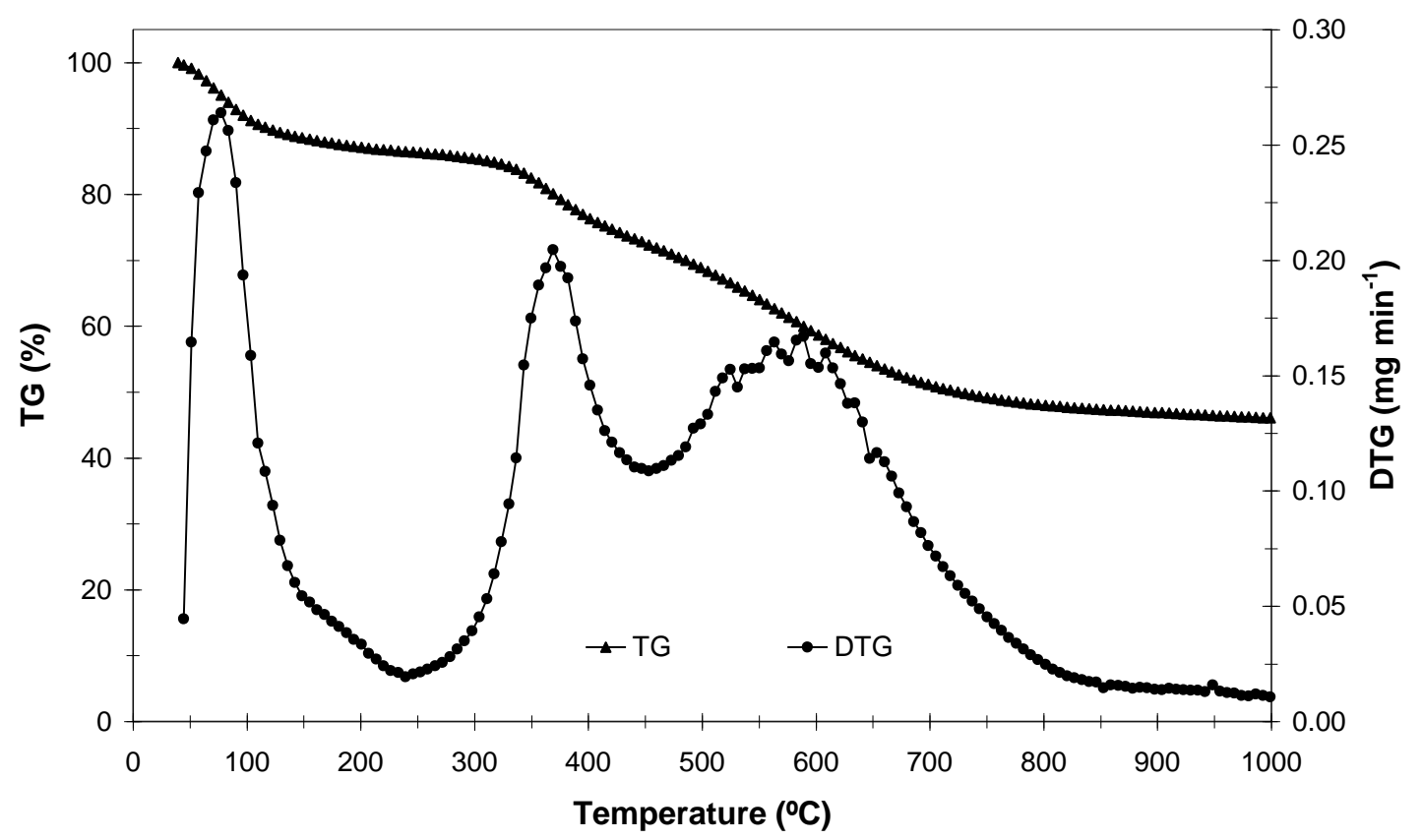

Figure 1. Evolution of mass loss (TG) and mass loss rate (DTG) with temperature during the temperature programmed carbonisation of the organic xerogel OX-6.5-212. 


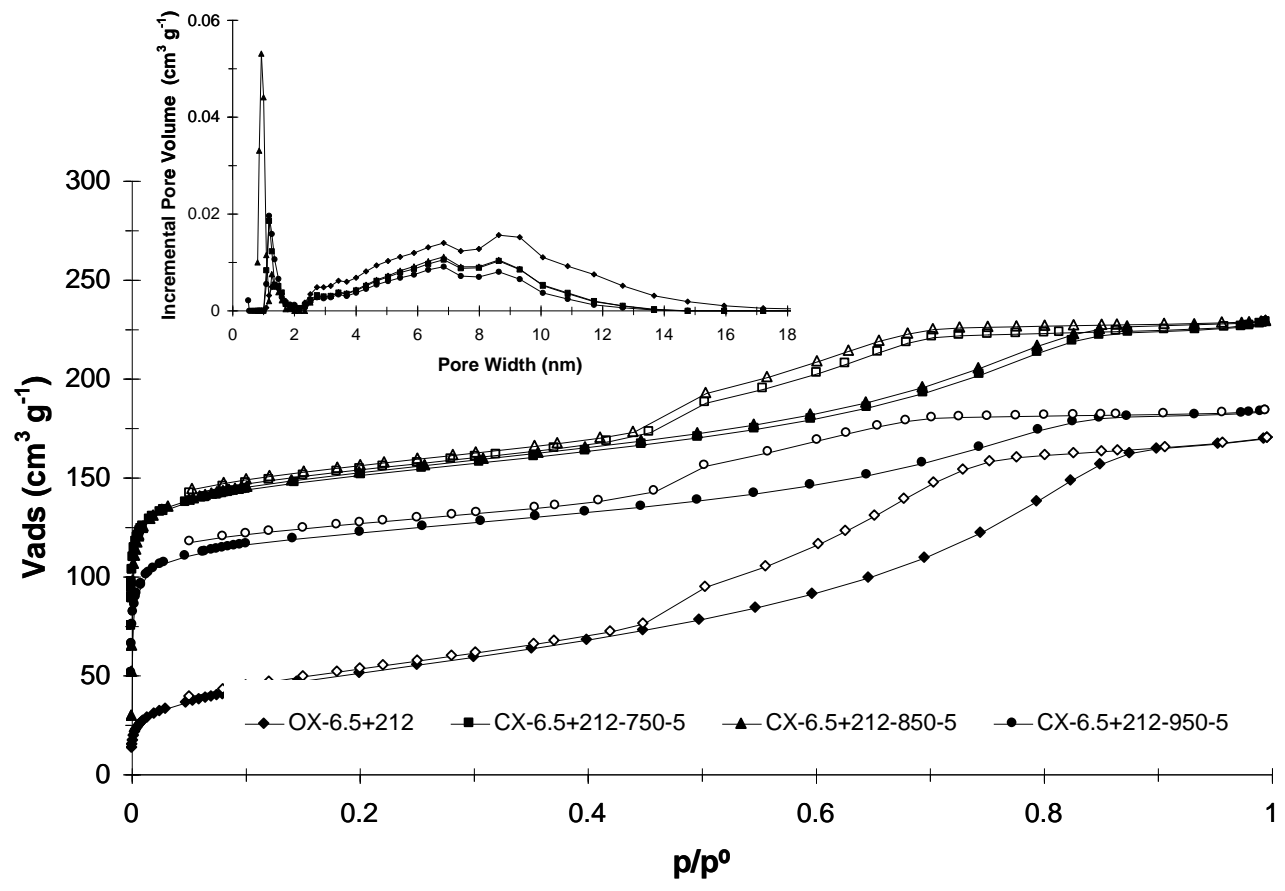

Figure 2. $\mathrm{N}_{2}$ adsorption-desorption isotherms at $-196^{\circ} \mathrm{C}$ and Pore Size Distribution of the organic xerogel OX-6.5+212 and the carbon xerogels (Series OX$6.5+212$ ) carbonised at different temperatures. 


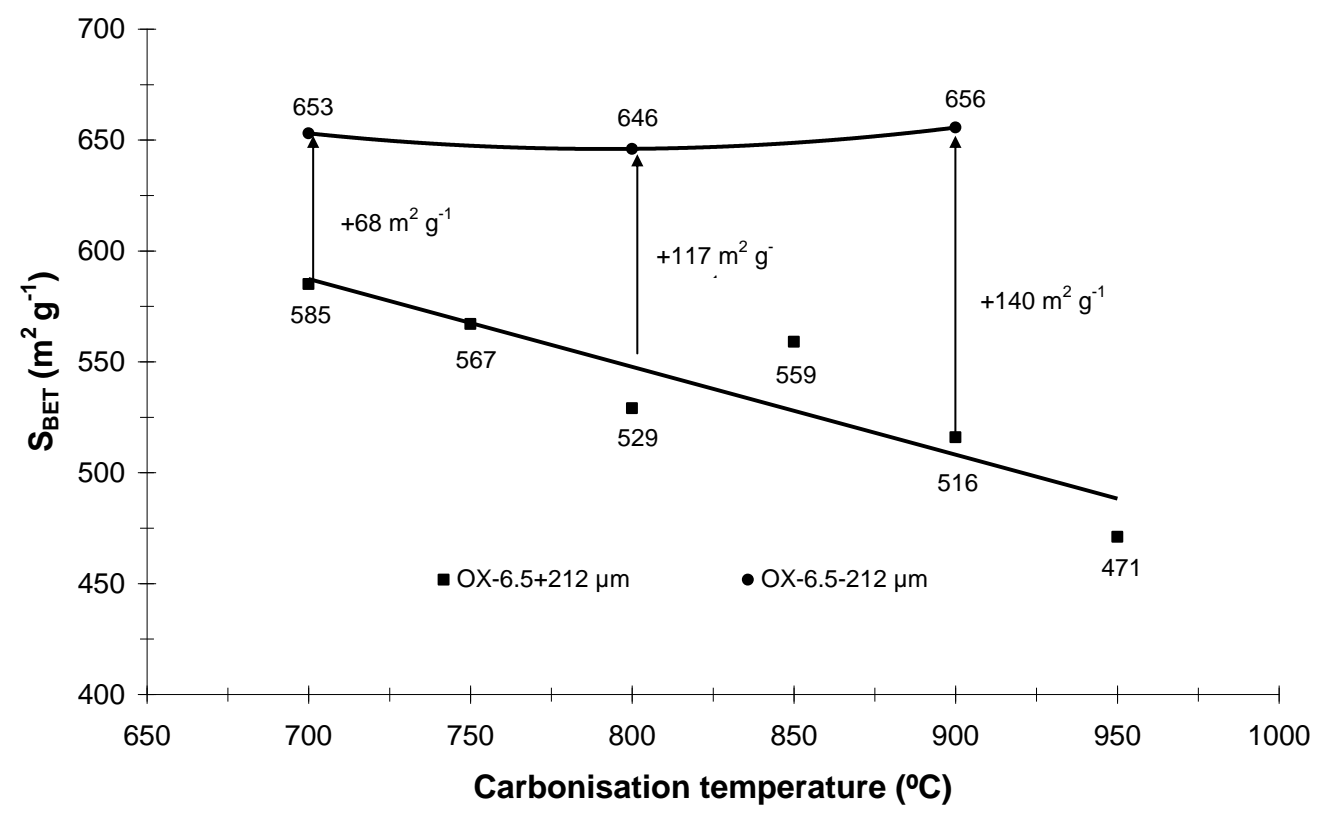

Figure 3. Variation of the specific surface area $\left(\mathrm{S}_{\mathrm{BET}}\right)$ of carbon xerogels with the carbonisation temperature and with the particle size of the organic xerogels. 


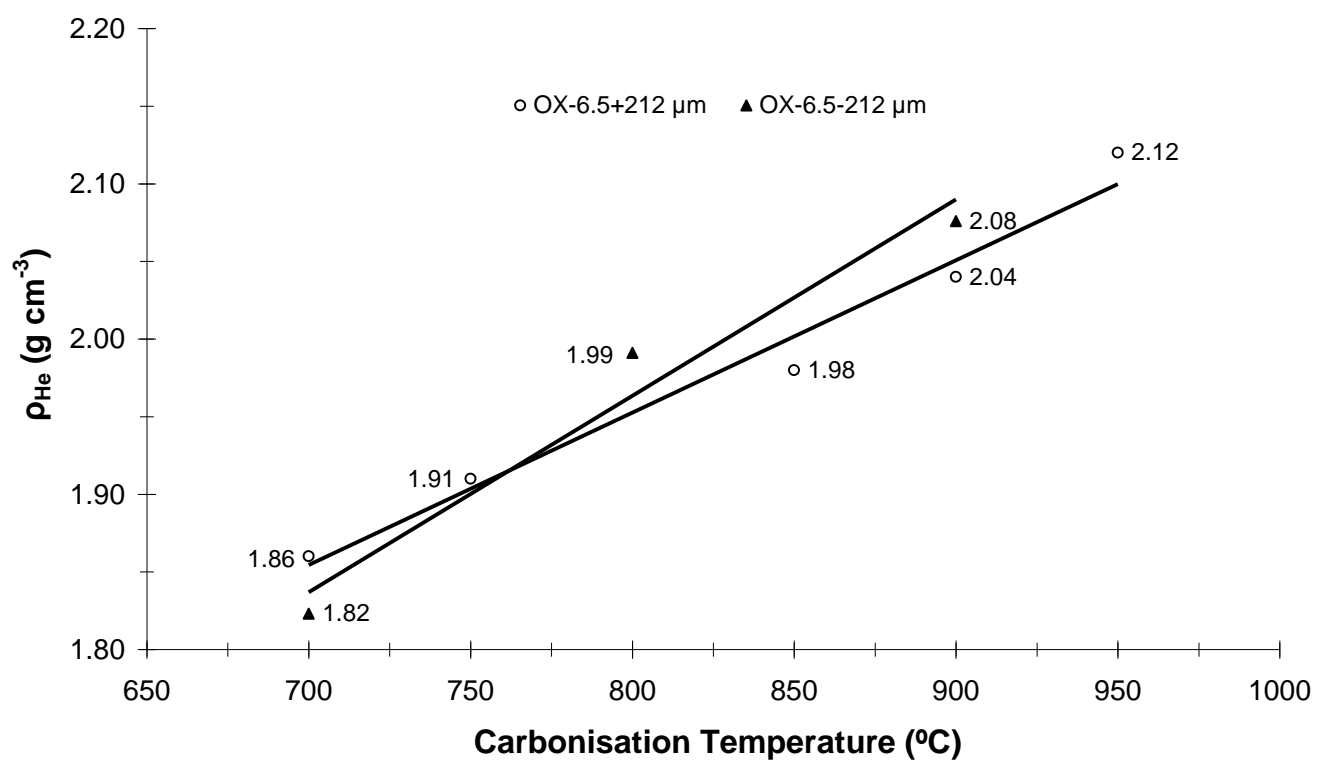

Figure 4. Variation of the helium (true) density of carbon xerogels with the carbonisation temperature and with the particle size of the organic xerogels. 


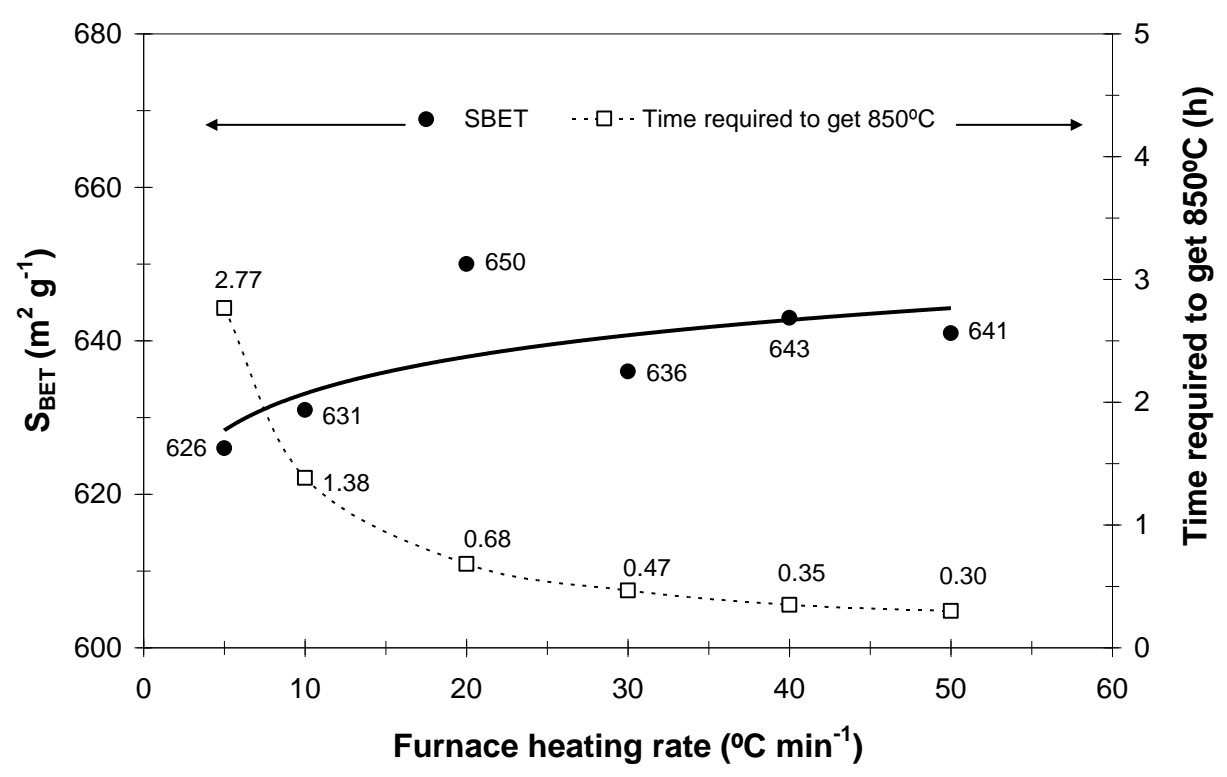

Figure 5. Variation of the specific surface area $\left(\mathrm{S}_{\mathrm{BET}}\right)$ of the carbon xerogels, and the time required to reach $850^{\circ} \mathrm{C}$, with the pyrolysis heating rate. 